University of Nebraska - Lincoln

DigitalCommons@University of Nebraska - Lincoln

Faculty Publications from the Department of Engineering Mechanics

Mechanical \& Materials Engineering,

Department of

$10-2008$

\title{
Impact Mechanics and High-Energy Absorbing Materials: Review
}

Pizhong Qiao

Washington State University, qiao@wsu.edu

Mijia Yang

University of Texas at San Antonio

Florin Bobaru

University of Nebraska - Lincoln, fbobaru2@unl.edu

Follow this and additional works at: https://digitalcommons.unl.edu/engineeringmechanicsfacpub

Part of the Mechanical Engineering Commons

Qiao, Pizhong; Yang, Mijia; and Bobaru, Florin, "Impact Mechanics and High-Energy Absorbing Materials: Review" (2008). Faculty Publications from the Department of Engineering Mechanics. 62.

https://digitalcommons.unl.edu/engineeringmechanicsfacpub/62

This Article is brought to you for free and open access by the Mechanical \& Materials Engineering, Department of at DigitalCommons@University of Nebraska - Lincoln. It has been accepted for inclusion in Faculty Publications from the Department of Engineering Mechanics by an authorized administrator of DigitalCommons@University of Nebraska - Lincoln. 


\title{
Impact Mechanics and High-Energy Absorbing Materials: Review
}

\author{
Pizhong Qiao, ${ }^{1}$ Mijia Yang, ${ }^{2}$ and Florin Bobaru ${ }^{3}$ \\ 1 F.ASCE, Professor, Department of Civil and Environmental Engineering \\ and Wood Materials and Engineering Laboratory, Washington State University, \\ Pullman, WA 99164-2910; email qiao@wsu.edu \\ 2 Assistant Professor, Department of Civil and Environmental Engineering, \\ University of Texas at San Antonio, San Antonio, TX 78249-0668 \\ 3 Associate Professor, Department of Engineering Mechanics, \\ University of Nebraska-Lincoln, Lincoln, NE 68588-0526
}

\begin{abstract}
In this paper a review of impact mechanics and high-energy absorbing materials is presented. We review different theoretical models (rigid-body dynamics, elastic, shock, and plastic wave propagation, and nonclassical or nonlocal models. and computational methods (finite-element, finite-difference, and mesh-free methods. used in impact mechanics. Some recent developments in numerical simulation of impact (e.g., peridynamics) and new design concepts proposed as high energy absorbing materials (lattice and truss structures, hybrid sandwich composites, metal foams, magnetorheological fluids, porous shape memory alloys. are discussed. Recent studies on experimental evaluation and constitutive modeling of strain rate-dependent polymer matrix composites are also presented. Impact damage on composite materials in aerospace engineering is discussed along with future research needs. A particular example for the design of a sandwich material as an impact mitigator is given in more detail. This brief review is intended to help the readers in identifying starting points for research in modeling and simulation of impact problems and in designing energy absorbing materials and structures.
\end{abstract}

Keywords: impact, energy absorption, damage, strain rate, shock waves, finite element method, finite difference method, nonlinear methods, honeycomb structures, sandwich structures, composite materials, blasting, dynamics

\section{Introduction}

Upon impact, a series of physical phenomena takes place: elastic, shock, and plastic wave propagation, fracture and fragmentation, perforation, and spallation (Meyers 1994). A rather complete list of monographs published on the subjects of stress waves and impact mechanics up to 1963 can be found in Kolsky (1963). Meyers (1994) and Nesterenko (2001) present dynamic behaviors of materials focusing on the analysis and design of energy absorbing materials and structures capable of resisting impact and mitigating blast. Catastrophic failures of aerospace structures due to impact damage, such as that of the Columbia space shuttle, demonstrated the pressing need for continued efforts from the research community on impact resistant materials. Civil and military applications require designing high performance and high energy absorbing materials and structures. For example, in the aerospace industry, new composite wing structures resisting hail and bird impacts are of relevance.

In what follows we provide a review of: 1) modeling of impact mechanics; 2) impact and damage for composites and sandwich structures, including strain rate-dependent material modeling and testing; and 3) development of energy absorbing materials. The literature in each of these areas is far too vast to permit an exhaustive account of all significant contributions in each field. This review is intended to help the readers identify starting points for research in the important field of modeling, simulation, and design of energy absorbing materials and structures.

\section{Modeling and Simulations of Impact Mechanics}

Analytical models for impact mechanics can be classified in four categories: 1) models based on rigid-body dynamics; 2) models for propagation of stress waves in perfectly elastic materials; 3 ) models for propagation of stress waves through solids which are not perfectly elastic, such as shock and plastic waves; and 4) nonlocal or nonclassical models able to describe spallation and fragmentation upon impact. From the point of computing the solutions of initial and boundary value problems generated by the analytical models mentioned previously, the numerical methods used in the literature fall under the following classifications: element-based (e.g., finite-element methods), finite-difference methods, and mesh-free methods (e.g., smoothparticle hydrodynamics, element-free Galerkin, Peridynamics). Depending on the referential used they can be Lagrangian (the computational grid follows the material), Eulerian (the computational grid is fixed and the material flows through it), or arbitrary Lagrangian-Eulerian codes (see, e.g., Meyers 1994, p. 174; Belytschko et al. 2000). Next we provide brief descriptions of the analytical models, simultaneously emphasizing the differences among them.

\section{Models for Impact Mechanics}

\section{Rigid-Body Dynamics Model}

In rigid dynamics one assumes that when a force is applied to a point in a body, all the points in that body are set in motion in- 
stantaneously and the relative distances between any two material points never change. This rigid-body dynamics model is based on the impulse-momentum law for rigid bodies, adjusted with phenomenological observations of elastic and inelastic restitution. Goldsmith (1960) and Kolsky (1963) present central impact, rotational impact and eccentric impact problems using this model. Brach (1991) also uses this approach to model rigid impact of objects with various shapes. The loss of energy that takes place between two bodies at impact is taken into account by means of the coefficient of restitution. The coefficient of restitution $(e)$ is defined as

$$
e=\left(v_{2 f}-v_{1 f}\right) \div\left(v_{20}-v_{10}\right)
$$

where $v_{1 f}$ and $v_{2 f}=$ velocities of the $m_{1}$ and $m_{2}$ impacting masses after impact, respectively, and $v_{10}$ and $v_{20}=$ velocities of $m_{1}$ and $m_{2}$ before impact, respectively; $m_{1}$ and $m_{2}=$ masses of the two impacted objects, respectively.

The rigid-body dynamics model for impact has serious limitations. It cannot describe transient stresses, forces, or deformation produced. When the forces of contact are applied over very short periods of time and local deformation is significant, the effect of stress waves propagating inside the body must be considered for a better approximation of the reality.

\section{Stress Wave Propagation in Perfectly Elastic Media}

Impact generates stress waves that propagate strain energy away from the region of impact. If the energy transformed into elastic vibrations amounts to a large fraction of the total energy, the rigid-body dynamics model is not applicable any more, and the approach based on wave propagation (or the transient model) is more suitable. Using this model, Goldsmith (1960) studies, among other topics, the longitudinal impact of two rods, the transverse impact of a mass on a beam, the tensile impact of a mass on a rod, and the effect of viscoelasticity on impact behavior. For example, the displacements of a rod produced by an impulsive load can be expressed in a form representing standing waves as

$$
\begin{aligned}
u & =-\left\{\frac{\sigma_{0} t^{2}}{2 \rho L}+\frac{2 \sigma_{0} L}{\pi^{2} E} \sum \frac{(-1)^{i}}{i^{2}} \cos \left(\frac{i \pi x}{L}\right)\left[1-\cos \left(\frac{i \pi c_{0} t}{L}\right)\right]\right\} \\
& =1,2,3, \ldots
\end{aligned}
$$

with the initial and boundary conditions as

$$
\begin{aligned}
& v=\frac{\partial u}{\partial t}=0, \quad t=0, \quad 0 \leqslant x \leqslant L \\
& \frac{\partial u}{\partial x}=0, \quad x=0, \quad t \geqslant 0 ; \quad \frac{\partial u}{\partial x}=-\frac{\sigma_{0}}{E}, \quad x=L, \quad t \geqslant 0
\end{aligned}
$$

where $L=$ length of the bar; $-\sigma_{0}=$ compressive stress applied at $x=L$ at $t \geq 0 ; E=$ Young's modulus; $\rho=$ density of the bar; $v=$ velocity; and $t=$ time.

Zukas et al. (1992) discusses the transient model of considering wave propagation in detail. For high velocity impacts, the transient model must be used in order to capture the real time stress wave history. However, the transient model, which does not consider contact deformation, cannot capture the local deformation due to projectile impact. The contact stresses generated at the impact of two bodies allow for determining contact duration, local deformation, and damage. Hertz theory (Johnson 1985) has been used to obtain the force-deformation relationship and to predict the contact duration and the maximal indentation.
The Hertz contact formula, expressing the relationship between the magnitude of the normal contact force and the normal deformation, is

$$
F=K_{c} \alpha^{3 / 2}
$$

where $K_{c}=$ contact stiffness; $\alpha=$ normal deformation (or compression) between the two colliding bodies; and $F=$ normal contact force. Combining with the equation of motion of the corresponding beams or plates, the contact force history and contact duration can be solved (see, e.g., Goldsmith 1960; Yang and Qiao 2005a,b).

\section{Stress Wave Propagation in Solids That Are Not Perfectly Elastic:} Shock and Plastic Waves

The elastic contact impact model can be extended to the cases where the plastic deformation occurs in a contained area. The force-deformation equation is often modified by adding a damping term to reflect dissipation in the contact area, thus allowing to effectively model the contact area as a spring-damper system as

$$
F=F_{c}(\alpha)+F_{v}(\alpha, \dot{\alpha})+F_{P}(\alpha, \dot{\alpha})
$$

where $F_{c}=$ elastic or conservative part of the contact force; $F_{v}=$ viscous damping part; $F_{p}=$ dissipation part due to the plastic deformation; and $\alpha$ and $\dot{\alpha}$ and $=$ deformation and the deformation rate between the target and projectile, respectively. Kinematic (nonpenetrating) and mechanical constraints must be satisfied at the contact surface between colliding bodies. The mechanical constraints are defined using the laws for normal and tangential forces generated during the contact process. The Lagrange multiplier method and penalty method are the two methods most frequently used for implementing contact-impact algorithms and analyzing contact-impact problems (see, e.g., Zhong, 1993). Friction is most often modeled using Coulomb's law, and the normal contact force is mostly modeled using Hertz contact law; however, modifications that include micromechanical effects have been proposed as well, especially in the finite-element literature (see, e.g. Wriggers et al., 1990, for implicit algorithms, and Wang et al., 2007, for explicit algorithms).

When the plastic strains become large and prevalent in the target, the elastic wave propagation model can no longer be applied to analyze such impact problems. The review in Goldsmith (1960) presents, in detail, the two most-used approaches: the hydrodynamic theory of the behavior of solid bodies, and the theory of plastic wave propagation. In the hydrodynamic theory, the permanent deformation happens with a sudden change of density. An equation of state relating pressure to density changes and temperature or entropy is needed in addition to the laws of conservation of momentum, energy and mass (Goldsmith 1960). In the theory of plastic strain propagation, the material is considered incompressible in the plastic domain and a temperature-independent equation of state (constitutive equation that relates stresses, strains and strain rates. is used in conjunction with the equations of motion. One-dimensional theories that attempt to simplify the problem of the plastic wave propagation have been proposed (Jones et al., 1997). The results in Jones et al. (1997) match the continuum results for the analysis of plastic wave propagation in the Taylor impact test, in which a cylindrical specimen impacts a rigid flat target perpendicularly in order to determine its mechanical behavior at high strain rates. Molinari and Ravichandran (2004) use the Lagrangian multiplier method to formulate the solution of steady plastic shocks in 
metals. An explicit formula is obtained for the characteristic shock width, and the effect of parameters like strain rate sensitivity and flow stress resistance on the shock profile is analyzed. They also provide information on the viscous response of materials subjected to very high loading in the shock wave experiments.

\section{Nonlocal Models}

Recognizing that actual materials have microstructures influencing the response to wave propagation, impact, damage and fracture, a large number of studies have focused on theories that account for the microstructure. A large variety of nonlocal models, that can capture size effects, regularize strain softening problems and avoid mesh sensitivity in numerical computations, have been introduced in the past three decades. A comprehensive review on the progress in the nonlocal models of integral type with thorough discussion of the physical justification, advantages, and numerical applications is given in Bazant and Jirasek (2002). Besides nonlocal models in elasticity, Bazant and Jirasek (2002) review models in nonlocal plasticity and damage, including cohesive zone models for fracture. Analytical results are possible for special cases for nonlocal models and some are presented in, for example, the monographs by Kunin (1982), and by Erofeyev (2003) which discusses wave processes in solids with microstructure. One of the factors that have delayed the widespread adoption of nonlocal formulations by industry has been the difficulty of correlating them to existing constitutive models that have performed well under certain strain rates and thermal ranges. The need to develop models and numerical tools to describe size effects in materials that standard theories cannot capture has promoted the development of many theories for nonlocal plasticity and damage. Several issues still need resolution in nonlocal plasticity models developed in, e.g., Eringen (1981), Bazant and Lin (1988), Svedberg (1996), Polizzotto et al. (1998), and Gao and Huang (2001). Bazant (1991) proposes a statistical nonlocal model, in which failure at a point of a material depends not only on the stress at that point but also on the average stress within a certain volume of the material. A considerable amount of work has been dedicated in the past few years to cohesive zone models based on the ideas of Dudgale (1960) and Barenblatt (1962). Computer implementation of the cohesive zone model has been proposed by Needleman (1987), Camacho and Ortiz (1997), and Ortiz and Pandolfi (1999). Although many issues still remain to be clarified in cohesive zone models (see Bazant and Jirasek 2002), these models have been recently integrated in some commercial finite-element codes, such as ABAQUS (SIMULIA, Providence, R.I.). The ultimate test for these methods is how well they can capture complex failure mechanisms in impact problems for composite and other heterogeneous materials. The use of non-local models for spallation in impact problems is investigated in Xie (2005).

A new nonlocal method, the peridynamic formulation, developed specifically for dealing with fracture and dynamic failure has been recently proposed by Silling (2000) and Silling et al. (2007). One of the main features of peridynamics is the spontaneous formation of discontinuities, which can be effectively used to capture material behavior at impact, like spallation and fragmentation processes (see, e.g., Silling and Askari, 2005; Xie, 2005). Peridynamics replaces the spatial derivatives from the equations of motion of classical mechanics with an integral of force density over a certain volume (Silling, 2000), thus eliminating mathematical and practical difficulties of treating strong discontinuities, such as cracks:

$$
\rho \ddot{u}=\int_{R} f\left(u\left(x^{\prime}, t\right)-u(x, t), x^{\prime}-x\right) d V_{x^{\prime}}+b
$$

and $f$ is defined as

$$
f(\eta, \xi)=\frac{\partial w}{\partial \eta}(\eta, \xi) \quad \text { with } \eta=u^{\prime}-u \quad \text { and } \xi=x^{\prime}-x
$$

where $f=$ pairwise particle force (per volume squared); $w=$ pairwise elastic potential for microelastic materials; $u=$ displacement vector; $\rho=$ density; and $b=$ body force.

In the peridynamic model, all forces are long-range as in other nonlocal continuum theories, such as those described in Kunin (1982) and Rogula (1982). A discussion of the relation between nonlocal theories and atomistic models can be found in, e.g., Chen et al. (2004). In Silling (2000), various properties of peridynamic models and the relationship to the classical continuum mechanics theories are presented in detail (isotropy, elasticity, wave dispersion, etc.). Silling et al. (2003) and Bobaru et al. (2008) discuss the peridynamic formulation for a one-dimensional bar, and the convergence of the peridynamic solution to the classical one in the limit of short-range forces is shown. The propagation of discontinuities, such as shock waves, has been analyzed using flux-corrected transport integration algorithms in Xie's (2005) master thesis. The review of the numerical implementation and results with peridynamics is given in the section entitled "Peridynamics and other Nonlocal Numerical Methods."

\section{Computational Models}

Computational models can be powerful tools helping the modeling and the design of new energy absorbing materials. Although important progress has been made in the past decades to simulate damage and failure processes taking place at impact, penetration, and fragmentation, much work remains to be done. Numerical modeling used as a tool to predict the physical behavior of material systems can help in designing optimal materials and structures. The field of optimal design of energy absorbing materials is still in its infancy.

\section{Finite-Element and Finite-Difference Methods}

Based on the impact models reviewed in the previous sections, numerous computational techniques have been developed to simulate impact phenomena. One of the most widely used computations method in this area has been the finite-element method (FEM). Commercial software, like ABAQUS, LS-DYNA (Livermore Software Technology Corp., Livermore, Calif.), PAM-Crash (ESI North America, San Diego, Calif.), implement algorithms that include modeling of contact and are capable of simulating impact conditions (see, e.g., Hallquist et al., 1985; Hallquist, 1993). Many problems, such as impact on composite materials, are still difficult to model and/or the results are not satisfactory with finite-elements. A review of FEM techniques used to simulate contact impact processes is given in Zhong (1993). Pandolfi et al. (1999), Repetto et al. (2000), and Mota et al. (2003) use arbitrary Lagrangian-Eulerian (ALE) methods to study impact damage and failure in marine structures and materials. Zukas and Scheffler (2001) study the effects of lamination and spacing on penetration of monolithic and multilayered targets.

Finite-difference methods (FDM) have also been used for impact simulations. The monograph by Zukas (2004) provides ample examples of the performance and existing difficulties in modeling impact, erosion, fragmentation with Eulerian codes, 
which historically have been developed in the context of FDM. Zhang and Ballman (1996) propose a finite-difference procedure to simulate the frictional contact-impact responses at the crack edges. Numerical examples show the influence of the contact impacting of crack edges on the history of dynamic stress intensity factors. Recently, Yang and Qiao (2007) conducted a finitedifference simulation for low and high velocity impact on sandwich beams.

Although Langrange codes (mainly used in the FEM) are starting to have difficulties when large distortions are involved, and Eulerian approaches (used in the FDM) pose question of how to deal with the motion of surfaces and interfaces, material transport, etc., the ALE method (see, e.g., Belytschko et al. 2000) has received more attention lately as the aim is to capture the advantages of both Eulerian and Lagrangian methods and reduce their disadvantages. The cost involved with performing an ALE analysis of impact problems is detailed in Zukas (2004). Simulations of impact, ductile failure, and fragmentation using the ALE formulation are found in, e.g., Camacho and Ortiz (1997), Johnson et al. (2001).

Some of the remaining problems of grid-based methods in modeling impact and large deformations are related to dealing with material separation (in fragmentation) and capturing inhomogeneities in the deformation and how these stress concentrations lead to fracture and material failure. To a certain extent, these problems are addressed by mesh-free (or mesh-less) methods reviewed next.

\section{Mesh-Free Methods}

Mesh-free methods are numerical techniques in which there is no fixed connectivity between the discretization nodes, and they are advantageous when simulating impact failure, penetration, and fragmentation. Mesh-free methods can be developed for continuum (solids and fluids) or for particle-based (granular materials) formulations. One of the first such methods is the smooth particle hydrodynamics (SPH), proposed in the 1970s (Lucy, 1977; Gingold and Monagham, 1977). Meshless methods have been used extensively in simulating large deformations and dynamic fracture in solids. Libersky and Petschek (1991) and Swegle et al. (1995) adapted the SPH methods to solid mechanics problems based on the strong formulation of the conservation equations. The SPH method has also been implemented in the LS-DYNA code since 1993. Belytschko et al. (1994) and Liu et al. (1997) developed mesh-free methods-i.e., the element free Galerkin (EFG) method and the reproducing kernel particle method-based on the weak form of the linear momentum balance equations. The EFG method has been used in static and dynamic fracture simulations (Belytschko et al. 1995). A benchmark impact problem of the Taylor experiment has been conducted and validated in Belytschko and Tabbara (1996) using the EFG method. Banerjee et al. (2005) uses the material point methods (Sulsky et al. 1994; 1995) for simulations of impact, penetration, and fragmentation.

Mesh-free methods are usually more computationally demanding than grid methods, and this is one reason for which mixed continuum-particle formulations have been proposedsee, e.g., Fahrenthold and Horban (2001), Johnson et al. (2001), and Johnson and Stryk (2003). These methods, however, are subject to tensile instability and numerical fracture problems. Shivarama and Fahrenthold (2004) suggest a hybrid particle-finite-element method, which avoids tensile stability and numerical fracture problems and eliminates the requirement for special treatment of particle-to-element contact-impact. A modified version of this hybrid particle-finite-element formulation is proposed in Park and Fahrenthold (2005).

\section{Peridynamics and Other Nonlocal Numerical Methods}

Cohesive zone models discussed in the section entitled "Nonlocal Models" have been used to simulate fracture and fragmentation-see, e.g., Andrews and Kim (1998). Zhou et al. (2005) studied cohesive model-based fragmentation analysis considering effects of strain rate and initial defects distribution. Cohesive zone models have been used in the context of finite-elements and, as a consequence, they suffer from the same problems gridbased methods do.

The peridynamics model (see the section entitled "Nonlocal Models") leads naturally to a mesh-free numerical model well suited for simulating impact, penetration, and fragmentation problems (see Parks et al., 2008). A description of the mesh-free numerical discretization for peridynamics is given in Silling and Askari (2005), where the bond failure is related to the classical energy release rate in brittle fracture. Examples of impact of a rigid sphere on a brittle solid show the formation of a cone of Hertzian cracks matching well with the experimental evidence. Fragmentation due to impact on a thin brittle target is also modeled successfully in Silling and Askari (2005), Wei (2005), and Parks et al. (2008). Silling and Bobaru (2005) used peridynamics in simulating fracture and damage of nonlinear (rubber-like) membranes and nanofiber networks. An in-depth study of the effect of van der Waals forces on the failure of nanofibers networks is presented in Bobaru (2007). Other numerical and computational aspects of peridynamics are given in Weckner and Abeyaratne (2005) and Weckner and Emmrich (2005). Adaptive refinement strategies helpful in large-scale simulations of impact and damage in composites are currently being developed (Bobaru et al. 2008). Peridynamic simulations of damage and delamination of composite laminates under low-speed impact conditions are shown in $\mathrm{Xu}$ et al. (2008).

\section{Optimization}

Besides simulating material behavior at impact of predesigned energy absorbing systems, the idea of using numerical methods to compute the optimal design for energy absorbing structures to best utilize the energy absorption capacity of its components is very appealing. Computational design of energy absorbing structures requires good simulation tools capable of correctly simulating the complex material behavior that takes place at impact and penetration. As we discussed earlier, there are still many issues to be resolved before such simulation tools reach a satisfactory stage. Thus, so far, optimal design of energy absorbing systems has used simplified models of impact and deformation modes. Shape optimization methods have been used in designing energy absorbing structures, such as vehicle bumpers, car body, oil platform, etc. Hamza and Saitou (2005) studied design optimization of vehicle structures for crashworthiness using equivalent mechanism approximations, in which a network of rigid links with lumped mass and nonlinear springs approximates aggregated behaviors of structural members. Topology optimization has also been employed to design energy absorbing structures. Pedersen $(2002,2003)$ conducts a series of studies on topology optimization of energy absorbing frames, in which effects of geometrical nonlinearities and path-dependent behavior of the structure have been included. Soto (2004) analyzes structural topology optimization for crashworthiness under impact loading, with applications to vehicle front rail. 
Combining material and structural optimization and taking into account damage, cracks, plastic deformation, friction, shock waves, etc., still remains one of the great challenges for the next decades.

\section{Open Problems and Outlook}

Although numerical codes become more and more sophisticated, many problems related to accurately predicting real material behavior at impact and penetration remain to be solved. For example, it is still difficult (with finite-element codes like LSDYNA) to numerically predict the experimentally observed (Nemat-Nasser et al. 2007) localized failure, buckling, and selfcontact of energy-absorbing sandwich structures with foam cores under high-rate inertial loads. New modeling techniques and better computational tools, that may have to include multiscale models and simulations, are needed to tackle such complex problems. Another example of an important problem that current computational models cannot tackle is that of the dramatic effect on the ballistic performance of the ceramic tile by a thin tape applied on the impacted face (Sarva et al. 2007). A future numerical model of this phenomenon will allow performing optimal design of such systems, thus reducing the significant amount of guess work currently used in the experimental work.

Future modeling and simulation tools will have to be able to treat concurrently and in a unified manner the many failure mechanisms present at impact and penetration, such as dynamic cracking and fragmentation, dislocation generation, motion and entanglement, shear banding, melting, etc. This is because the penetration resistance (or energy-absorbing) characteristics are closely related to the fragmentation and pulverization mechanisms and the distribution of kinetic energy into the various failure mechanisms. The models that will be successful will most likely involve multiple scales as the physical phenomena responsible for material failure at high velocity impact act at these different scales. The material micromorphology and microstructure are responsible for the different microscopic failure modes that lead to dynamic microcracking, dislocation, twinning, shear banding, etc.

\section{High Energy Absorbing Materials and Structures}

Fiber composites, foams, magnetorheological (MR) fluids, and porous materials are the typical high energy absorbing materials; whereas sandwich or lattice systems represent an interdisciplinary concept by combining the areas of material selection, design, and function integration for meeting the high requirements of multifunctional modern materials. The sandwich systems take advantage of the properties of miscellaneous material components, e.g., low density of core, high bend resistance of face sheet and core combination, sound and vibration insulation, high energy absorption, high load-capacity at a low weight, and have been used as the primary energy absorbing materials in naval and military structures.

\section{Metal Plates and Polymer Matrix Composites with Strain Rate Dependent}

Metal plates and polymer matrix composites (PMCs) are the first used for personal protection for the defeat of small arm projectiles, and as backing plates, usually with ceramics, against larger projectiles and blast fragments. PMCs combine the beneficial properties of both polymer resins (ability to absorb and mitigate kinetic energy) and high performance fibers (high to ultrahigh elastic modulus and strength), possess higher specific strengths (ultimate tensile strength divided by density) than their metal counterparts, and are capable of providing equivalent ballistic protection at reduced weights. PMCs utilized for armor applications include fiberglass, aramid fiber, braided and woven composites, and polyethylene fiber composites. Shim et al. (1995) conduct research on modeling deformation, and damage characteristics of woven fabric under small projectile impact, in which the deformation and damage of woven fabric composites are simulated. Ambur et al. (2001) develop numerical simulations of high-energy impact over thin metal plates, in which the penetration and perforation process of the projectile over the metal plate are analyzed. Lee et al. (2003) develop advanced body armor system utilizing shear thickening fluids, which improves the ballistic penetration resistance of Kevlar fabric composites. Hogg (2006) summarizes current developments in using composites in armors and concludes that the current design of composite armor systems relies on experience, empiricism, and intuition to a great extent.

Under high velocity impact, the deformation response of the PMC can be highly strain rate dependent and nonlinear. Most of the existing analytical models and numerical software, which assume the deformation of the materials to be independent of strain rate and often linear, are incapable of simulating strain rate-dependent deformation and nonlinearity caused by the high strain rate impact (Goldberg et al., 2007). Several studies have been conducted to experimentally characterize the strain rate-dependent behavior of resin or PMC and to develop associated constitutive models, which can be incorporated into the micromechanics models and the nonlinear finite-element analysis (e.g., nonlinear finite-element code LS-DYNA) for the high velocity impact analysis of PMC structures.

Polymer matrix is known to have a strain rate-dependent deformation response. Daniel et al. (1995) study the strain rate dependence and nonlinearity of carbon/epoxy composites and conclude that the strain rate-dependence and nonlinearity is primarily driven by the epoxy matrix. The constitutive equations of metals based on plasticity and viscoplasticity are often adapted to model the nonlinear and strain rate-dependent deformation of polymer (Bordonaro, 1995; Goldberg et al., 2005). For example, the viscoplasticity theories are developed to account for hydrostatic stress in the nonlinear deformation response by applying variation of the Drucker-Prager yield criterion through modifying the definitions of the effective stress and effective inelastic strain (Li and Pan, 1990; Chang and Pan, 1997; Goldberg et al., 2005). Using the above-mentioned modification, Goldberg et al. (2005) develop the nonlinear constitutive model to account for the strain rate dependence and nonlinearity of the matrix and then implement it into a micromechanics model to obtain the effective composite deformation response under different loading rates. Goldberg et al. (2008) revise the analytical model in Goldberg et al. (2005) to account for the nonlinear unloading behavior, simultaneously including the effects of hydrostatic stresses on the nonlinear deformation.

Gilat et al. (2005) use small dog-bone-shaped samples for tensile tests and short hollow cylinders for shear tests to obtain the stress-strain curves of epoxy resins at both low and high strain rates. Epoxy resins under tension, compression, and shear are experimentally characterized using a full field optical technique for strain measurement, and the stress-strain curves over a wide range of strain rates $\left(10^{-5} / \mathrm{sec}\right.$ to $\left.10^{-1} / \mathrm{sec}\right)$ and temperature (room temperature to $80^{\circ} \mathrm{C}$ ) are obtained in Littell et al. (2008). 

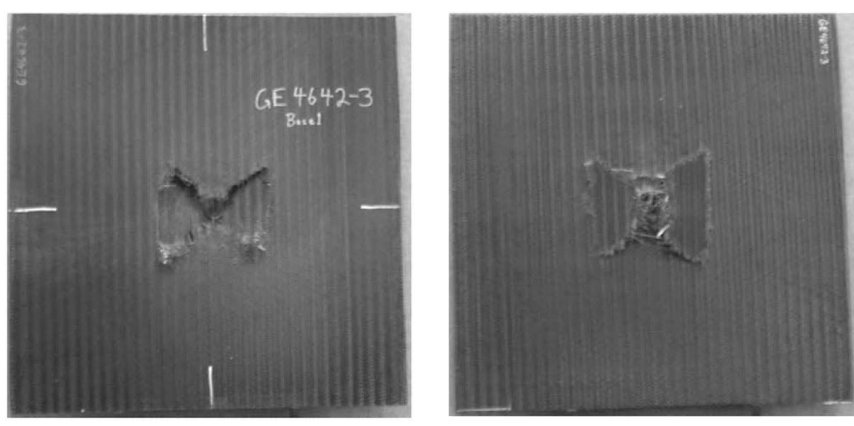

Figure 1. Failure modes of a braided composite impacted by a projectile at 192 m/s. (Courtesy of Wieslaw K. Binienda)

The full set of experimental data is useful for defining the internal state variables that can be used in the constitutive models for impact analysis (Goldberg et al. 2005).

The experimental strain rate-dependent data of polymer matrix and strain rate-dependent, nonlinear constitutive models are often implemented into micromechanics models to obtain effective composite properties, which are then input into the nonlinear finite-element code (e.g., LS-DYNA) for impact and failure analysis of composite structures. Zheng and Binienda (2008) adapt the state variable-based viscoplastic equations and implement them in strength of materials based micromechanics models to predict the nonlinear and strain rate-dependent deformation of the PMC. In their study, the state variable based viscoplastic equations originally developed for metals are modified in order to account for the effects of hydrostatic stresses, which are significant in polymers. The polymer and composite models as rate-dependent shell elements are implemented into explicit finite-element code LS-DYNA as user defined materials (UMATs). Cheng and Binienda (2008) propose a simplified methodology to model two-dimensional (2D) triaxially braided composite plates impacted by a soft projectile using an explicit nonlinear finite-element analysis code LS-DYNA. The numerical finite-element model captures the penetration threshold, deformation behavior and failure of two different 2D triaxial braided composites with different fiber architectures.

The continuum models that only consider strain rate effects cannot provide answers about failure regime of PMCs and metal plates. For impact applications, one has to include the energy dissipation mechanisms. The energy dissipating mechanisms with this type of materials are: formation of interlaminar cracks, breakage of fibers, shear away of lamina bundles and debris, and plastic deformation. Figure 1 shows a typical multilayer braided composite system with different failure modes (Binienda, 2004; Cheng and Binienda, 2006). Predicting failure and energy dissipation capacity of composite materials is far from being achieved. Cox and Yang (2006) give a general review for modeling failure mechanisms of structural composites and emphasize the difficult challenges of simulating diffuse and complex fracture patterns observed in these materials. Zhu et al. (2008) defined a new failure model capable of characterizing different failure modes of rate-dependent polymer matrix composite laminates under high velocity impact. Shear failure, delamination, and tearing failure are addressed, and the threedimensional micromechanics model with damage (Zhu et al., 2006) is implemented in the nonlinear finite-element code LSDYNA to analyze the penetration of composite laminates subjected to high velocity impact. The new peridynamic model (see the section entitled "Modeling and Simulations of Impact Me- chanics") offers promise to resolve some of these challenges (see $\mathrm{Xu}$ et al., 2008). A recent special issue dedicated to impact mechanics of composite materials, with particular attention to aerospace application, is provided by Qiao and Binienda (2008).

\section{Impact Damage in Composite and Sandwich Structures}

Composite and sandwich structures have been frequently used for many years in aerospace engineering related applications due to their lightweight properties. However, these materials are sensitive to impact damage. The majority of impact studies on composite and sandwich structures focus on the following four aspects: 1) dynamic response; 2) contact mechanics of composite and sandwich structures with foreign objects; 3) damage and failure modes of composite and sandwich structures under impact; and 4) effects of anisotropy and special core structures on impact responses. In this section we review the literature on damage and failure due to impact on composite and sandwich structures.

The impact damage and impact resistance of laminates and sandwich structures have been extensively investigated (see, e.g., Caprino and Teti, 1994; Thomsen, 1995; Tsai et al., 1998; Turk and Hoo-Fatt, 1999). Dobyns and Porter (1981) propose the prediction of the overall damage size of a carbon composite plate subjected to a low-velocity impact. Matemilola and Strong (1995) conduct an analytical study about impact-induced dynamic deformation and stresses in carbon fiber reinforced polymer composites, which provides a stress analysis tool for further damage assessment. Davies et al. (1995) develop a simple modeII fracture analysis for single circular delamination by treating glass fiber reinforced polymer composite as an isotropic material and show that a threshold force $P$ could be used to find the initiation of delamination. Reid and Zhou (2000) perform several experiments on the initiation of delamination and damage size from the impact process, exhibiting that the critical delamination force or energy could be observed from the contact force history curve. Conrad and Sayir (1998) capture the dynamic failure process of a foam sandwich subjected to a foreign object impact using a high speed camera, from which the failure mechanism involved in the impact event, i.e., core shear failure, debonding between the face sheets and core material, and face sheet tensile failure, is clearly depicted. Shipsha et al. (2003) study failure mechanism and modeling of impact damage in sandwich beams through an experimental investigation, and the different failure modes involved are characterized. Lim et al. (2004) study failure modes of foam core sandwich beams under static and impact loads. Different failure modes of sandwiches (Figure 2) with different density and face sheet dimensions under different impact velocities are characterized.

The dynamic response of sandwich structures with aluminum foam cores are analyzed in experiments performed by Nemat-Nasser et al. (2007). At high impact velocities, localized deformation of the metal foam is observed. The simulations using LS-DYNA crushable foam material model do not predict the localized deformation but do show changes in the deformation as the impact velocity is varied, which is seen in the experiments.

Core crushing is a special type of failure for honeycomb sandwich structures. Most of earlier work on core crushing of aluminum honeycomb sandwich structure is obtained by the aerospace and automotive industries. Magee and Thornton (1978) and Hexcel Corporation $(1964 ; 1968)$ conduct extensive research characterizing the crushing behavior of honeycomb. An attempt to calculate the crushing strength of bare honeycomb (without face 
plates) goes back to the work of McFarland (1963) in which the shearing of the walls in individual cells is modeled, but such a collapse model may not happen in reality. Wierzbicki (1983) predicts the mean crushing strength of an array of hexagonal cells from the known geometry of the cell and yield strength of the material and proposes a so-called folding element for aluminum structures. The research on crushing or indentation of honeycomb sandwiches with face sheet plates is limited, mainly because the constraint effects of face sheets on honeycomb core structures is difficult to be included. Wierzbicki et al. (1995) simplify the problem using a membrane on a rigid-plastic foundation and adopt a quasistatic model to simulate the impact response by assuming that the projectile is much heavier than the face sheets.

Closed form solutions are derived for the maximum deflection amplitude, the extent of plastic deformation, and the total energy absorbed as a function of the velocity and mass of projectile and the mechanical properties of the face plates and honeycomb core. A comprehensive experimental study in deformation and energy absorption of bare honeycombs and sandwich plates with honeycomb core is performed by Goldsmith and Sackman (1992).A cylindrical punch is used in static tests. In the dynamic tests, the blunt cylindrical strikers are launched with an initial velocity ranging from 10 to $40 \mathrm{~m} / \mathrm{s}$. The resulting deflections of the face plates in both the static and dynamic tests are 7-15 times larger than the thickness of face sheet plate, demonstrating that the membrane effect is very pronounced in such a case. Jamjian et al. (1994) derive a mathematical model of the impact problem and simulate this process. In their model, the face plate is considered to be rigid plastic and bounded at infinity. The sheet plate deformation is in a combined bending/membrane mode, and the honeycomb core is modeled as a rigid-plastic foundation. The numerical predictions of the maximum indentation of the projectile into the face plate are found to be within $10 \%$ of the experimental results; those of the lateral extent of damage are within $5 \%$ of the test results.

Most recently, Yang and Qiao (2008a) thoroughly evaluate the quasistatic crushing behavior of aluminum honeycomb materials using a combined experimental, analytical, and numerical approach. Based on their experimental characterization, the constitutive properties of the honeycomb cores under flat compression are approximated by an elastic perfectly plastic material with inclusion of hardening after densification. Two different cell size materials are tested and compared, and the effect of strain rate on the maximal crushing stress is studied. The experimental results show that the crushing platen stress is directly related to the relative density of core materials, and it can be associated with the strain rate, even though the effect of strain rates is not so dominant based on the conducted quasistatic tests. A simple physical model for the crushing wavelength and stress is proposed and compared with the experimental data and available formulas in the literature. It is observed that the crushing wavelength is close to the cell size and related to the geometric dimension and strain rate. The folding mechanism is also measured by the ARAMIS system (a photogrammetry technique, Trilion Quality Systems, West Conshohocken, Pa.; http://www. trilion.com), and the measured von Mises strains are compared with the numerical results from LS-DYNA, demonstrating that the folding mechanism is initiated by two plastic hinge lines formed at the cell corners. Multilayer effect is also investigated, which indicates that including the second layer slightly decreases the maximal crushing stress, but the simple superposition is still applicable for crushed multilayer sandwiches. Partial crushing due to small size cylindrical indenter is further studied, and the experiment shows that the partial crushing process

\section{Face thickness}

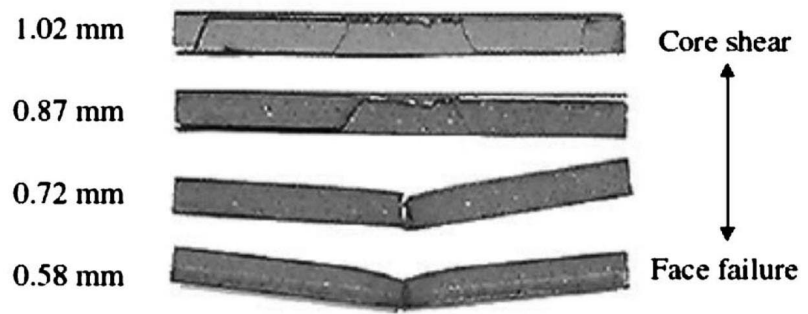

(a)

\section{Core density}

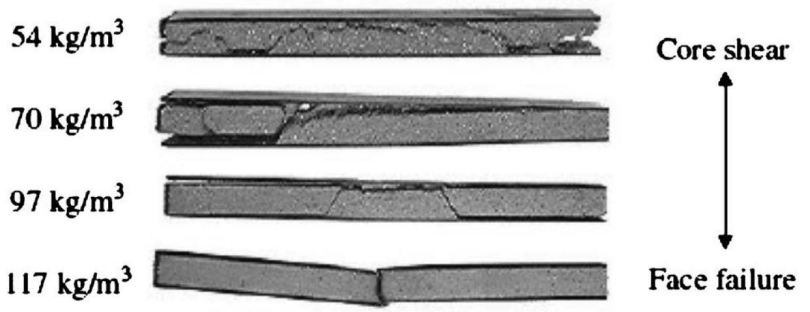

(b)

Figure 2. Failure modes of sandwich beams under impact forces (Lim et al. 2004) (a) effect of face sheet thickness; (b) effect of core density; the sandwich beam is $90 \mathrm{~mm}$ in span and $150 \mathrm{~mm}$ in length; the core is made of PVC foam, and the face sheets are made of Eglass fiber reinforced epoxy (reprinted with permission).

can be described by an elastic-plastic hardening material. Side impact process of honeycomb materials is also investigated, and the collapse band and its propagation process are captured.

Vaziri et al. (2006) study metal sandwich plates with polymer foam-filled cores. The role of low-density structural polymeric foams filling the interstices of the cores of metal sandwich plates is analyzed to determine the strengthening of the cores and the enhancement of plate performance under crushing and impulsive loads. Two different types of sandwich structures - square honeycomb and folded plate steel cores - filled with two densities of structural foam are studied. The outcome suggests that plates with foam-filled cores can perform as well, or nearly as well, as plates of the same weight with unfilled cores. Vaziri and Hutchinson (2007) study metal sandwich plates subjected to air shocks. Fluid-structure interaction is found to enhance the performance of sandwich plates relative to solid plates under intense air shocks.

\section{Ceramic Armors}

Ceramic armors are used for the containment of blast fragments and prevention of bullet penetration. They were developed strictly for projectile resistance with a high hardness and compressive strength with an advantage of light weight. The need for lighter protection materials for use in military aircraft brings about the use of ceramic armor materials. Ceramics offer an advantage over steel in weight reduction, and over all metals in impact energy absorption. The most common ceramic materials used for armor applications are alumina, boron carbide, silicon carbide, and titanium diboride. In armor structures, ceramics are usually backed by metal plates, with or without a composite layer sandwiched between them (see Figure 3) (Lopez-Puente et 


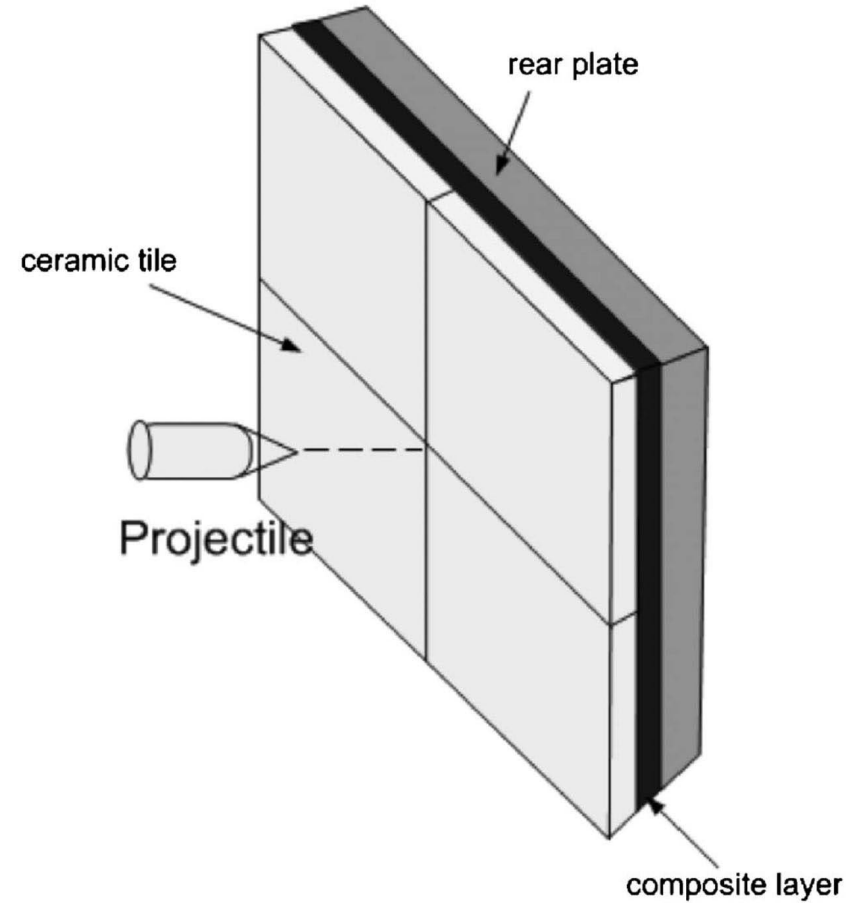

Figure 3. A layered armor composite system with ceramic facing. Adapted from Lopez-Puente, J., Arias, A., Zaera, R., and Navarro, C., "The effect of the thickness of the adhesive layer on the ballistic limit of ceramic/metal armours. An experimental and numerical study," International Journal of Impact Engineering, 32 (2005), pp. 321336; http://www.sciencedirect.com/science/journal/0734743X, with permission from Elsevier.

al. 2005). The energy dissipation mechanisms for these type of structures are: brittle failure and fragmentation of ceramics, delamination and delocalization of the fracture zone in the composite, and plastic deformation of the metal plate.

Lee and Yoo (2001) conduct an analysis of ceramic/metal armor system, in which the strain rate effect is considered and the ballistic limits for different ceramic/metal back plate ratios are derived. Cheng et al. (2003) perform experiments for the ballistic impact on a boron carbide plate, and they find that the loss of impact resistance of boron carbide is due to the phase transformation to the glassy form.

An interesting aspect of the ballistic performance of armor grade ceramic tiles has been experimentally investigated by Sarva et al. (2007). It is observed that restraining the impact-face of ceramic tiles with a membrane of suitable tensile strength, the ballistic performance is improved by $25 \%$ for a small increase in mass. The phenomenon is explained by the limiting effect the membrane has on the ejected material, which now works against the penetrator, eroding it and slowing it down. This type of effect would be a great and difficult benchmark test of numerical codes used in impact and penetration. New computational capabilities need to be developed to replicate the effects observed in Sarva et al. (2007).

\section{Lattice and Truss Structures}

The metal lattice or truss structures with or without waiting links can also be used in blast mitigation and armor design. Figure 4 (Rathbun et al., 2006) shows a typical square honeycomb sandwich system impacted by a blast wave, and the main mech-

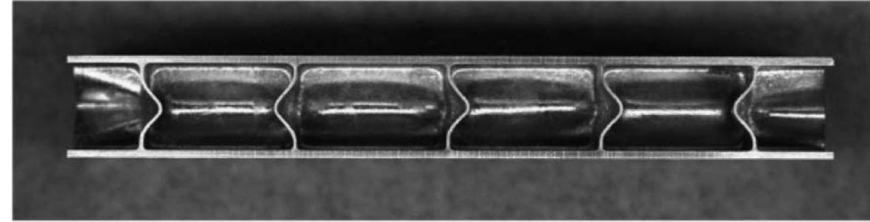

(a)

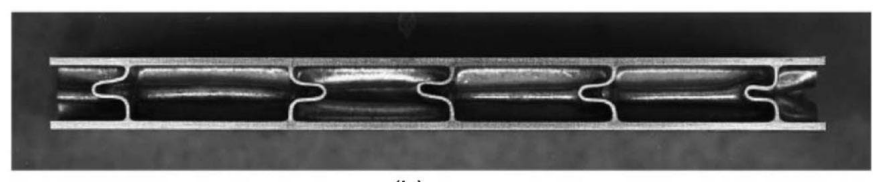

(b)

Figure 4. A square honeycomb sandwich energy absorbing system. Reprinted from Rathbun, H. R., Radford, D. D., Xue, Z., He, M. Y., Yang, J., Deshpande, V., Fleck, N. A., Hutchinson, J. W., Zok, F. W., and Evans, A. G., "Performance of metallic honeycomb-core sandwich beams under shock loading," International Journal of Solids and Structures 43 (2006), pp. 1746-1763; http://www.sciencedirect. com/science/journal/00207683, with permission from Elsevier.

anism of energy absorption: the kinetic energy of incident waves is dissipated mainly through the plastic buckling of the core struts.

Guruprasad and Mukherjee (2000) analyze layered sacrificial claddings under blast loading, which could be compared with the honeycomb core sandwich behavior, absorbing the ballistic energy by the progressive crushing process. Evans et al. (2001) conduct research on multifunctional metal sandwich structures, primarily used for blast mitigation. Xue and Hutchinson (2004) study blast resistant metal sandwich plates and compare the effect of different truss structures on impact resistance. Fleck and Deshpande (2004) also investigate the resistance of clamped sandwich beams due to shock loadings. The analysis of the type of failure of classical materials shows that localized failure is dominating in projectile impacts as well as blast impacts (Taylor and Vinson, 1990), which diminishes their effectiveness as armor systems. Therefore, lattice structures with waiting links are suggested to spread the localized damage and thus provide blast mitigation. The concept of lattice structures with waiting links has not yet been developed into products. The concept of lattice structure with waiting links is researched by Cherkaev and Slepyan (1995), who analyzed the loading responses of lattice structures with waiting links and explained the failure of a lattice structure under dynamic loading. Balk et al. (2001) further expand the waiting link concept and simulate the delocalization of damages in a lattice structure. Slepyan and Ayzenberg-Stepanenko (2004) include the effect of cracks into the lattice structure and conduct studies on dynamic fracture propagation. Dancila and Armanios (2002) suggest a similar concept in composites. Preliminary validation of the lattice structures with waiting links is presented in Ha and Dancila (2003). The waiting link concept could be transferred and applied to designing crystal lattices with a higher ballistic limit. Crystal lattice structures under dynamic loading are studied in, e.g., Pouget (1992; 1993). Pouget (1992) conducts a study about the stability of nonlinear structures in a lattice model for phase transformations in alloys. Pouget (1993) also studies the lattice dynamics and stability of modulated-strain structures for elastic phase transitions in alloys. Designing a new type of crystals with lattice structure of waiting links could provide a solution for new armor systems. 


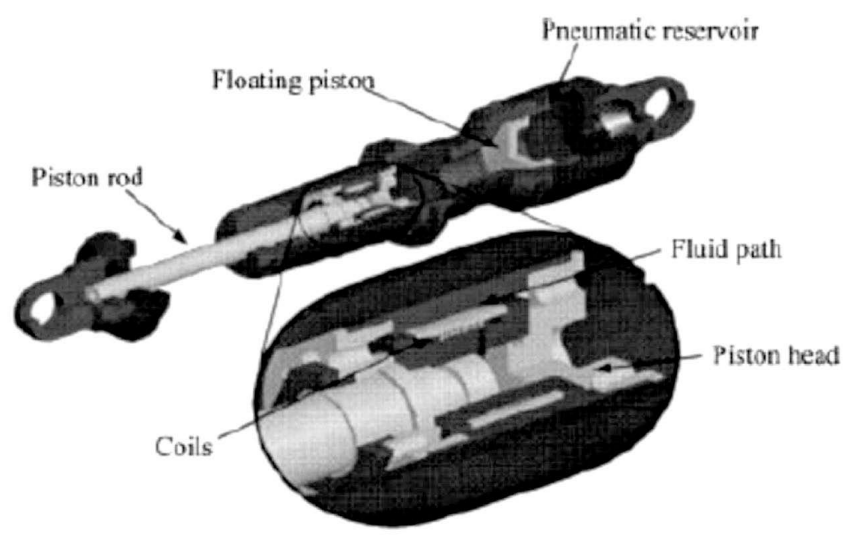

(a) An impact damper system

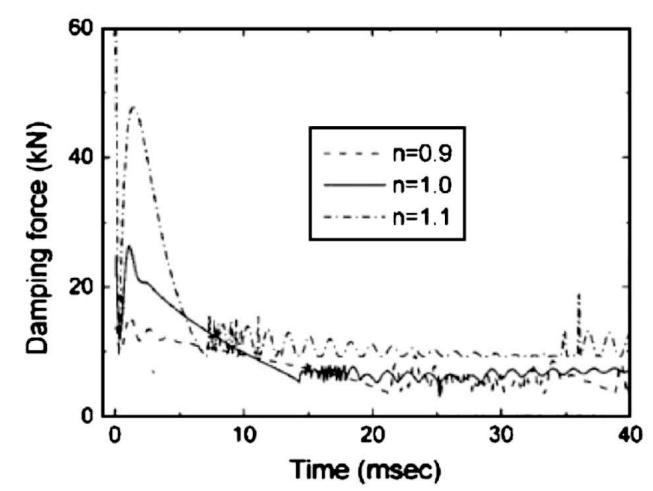

Figure 5. An impact damper MR fluid system: (a) an impact damper system; (b) damping force generated by the impact damper for different shear strain rate index $(n)$. Reprinted with permission of Sage Publications from Lee et al. (2002).

\section{Magnetorheological Fluids}

MR fluids, having ferromagnetic ultrafine particles dispersed, are used as high energy absorbing materials. Normally, MR fluids behave like regular motor oils; however, when a magnetic field is present, they become viscous within milliseconds. The viscosity leads to energy dissipation when the MR fluid is sheared. Models for MR fluids relate the shear stress with a power of the shear strain. A subunitary power index corresponds to a shear-thinning fluid, whereas a supraunitary

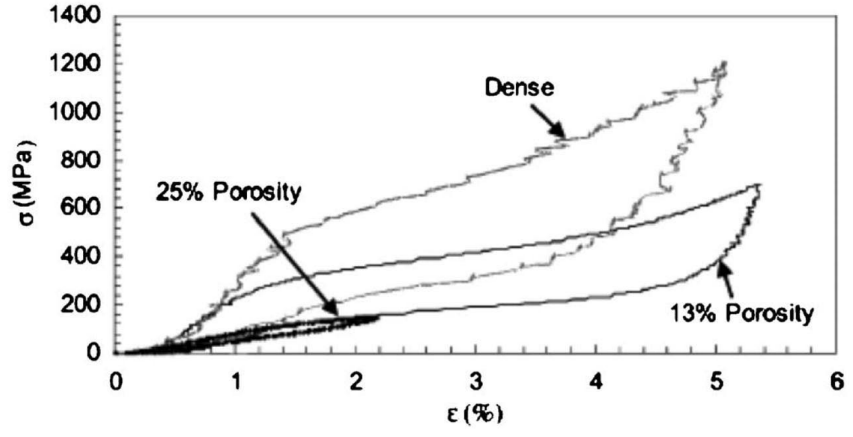

Figure 7. The hysteresis loops of the stress-strain curves for porous NiTi material. Reprinted from Zhao, Y., Taya, M., Kang, Y. S., and Kawasaki, A., "Compression behavior of porous NiTi shape memory alloy," Acta Materialia 53 (2005), pp. 337-343, with permission from Elsevier.

power index gives a shear-thickening fluid. Figure 5(a) shows an impact damper system (Lee et al. 2002) which uses a MR fluid. The damping force generated by the damper for different shear strain power indices is shown in Figure 5(b)(Lee et al., 2002).

The majority of MR fluids are used in control devices, such as semiactive MR dampers used in earthquake mitigation (Yang et al. 2004). Research on MR dampers has focused on low velocity and frequency applications (Jolly et al., 2000). Ahmadian et al. $(2001 ; 2002)$ and El et al. (2002) have shown the capability of MR fluids in handling impulsive loads for low velocities. It is still not known how to exploit MR fluids for high velocity impulsive loads.

\section{Porous NiTi Shape Memory Alloys}

Miyoshi et al. (1999) design porous NiTi shape memory alloys for high energy absorption applications. As the density of porous NiTi is less than that of its solid version, it is much lighter. The porous NiTi, however, can absorb almost the same deformation energy as its solid counterpart does for the same volume. Kang et al. (2001) produce a ductile porous NiTi rod using spark plasma sintering (SPS) method, and its energy absorbing behavior is discussed in Zhao et al. $(2005 ; 2006)$.

Figure 6 shows a Porous NiTi SMA manufactured by spark plasma sintering (Zhao et al., 2005), in which different porosities are realized. The hysteretic behavior of these materials shown in Figure 7 gives the main mechanism that contributes to the energy dissipation in the material.
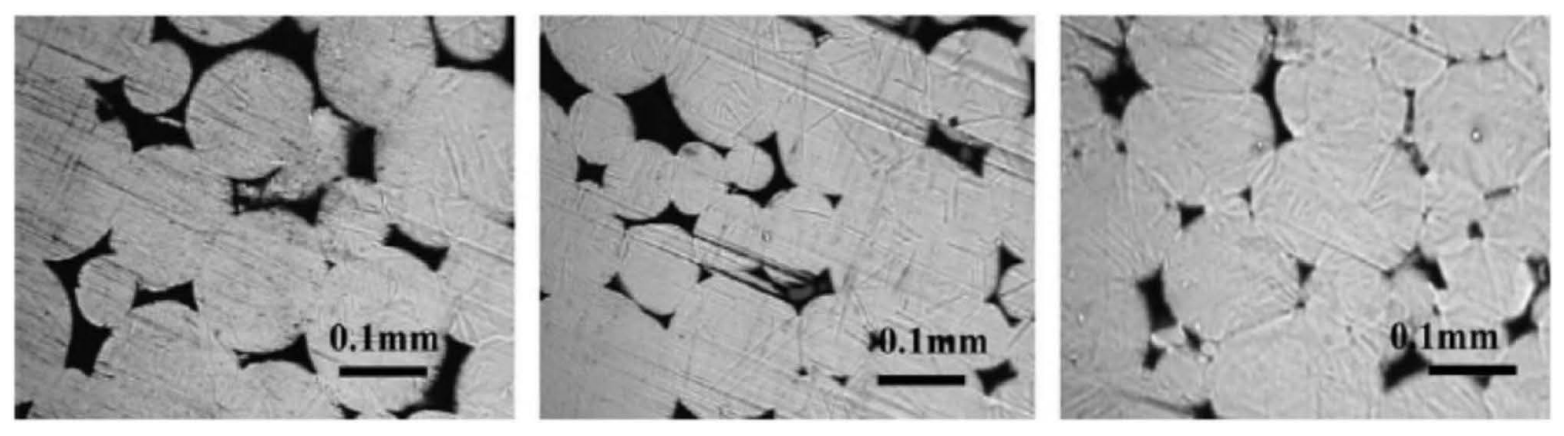

Figure 6. Porous SMA material system. Reprinted from Zhao, Y., Taya, M., Kang, Y. S., and Kawasaki, A., “Compression behavior of porous NiTi shape memory alloy," Acta Materialia 53 (2005), pp. 337-343, with permission from Elsevier. 


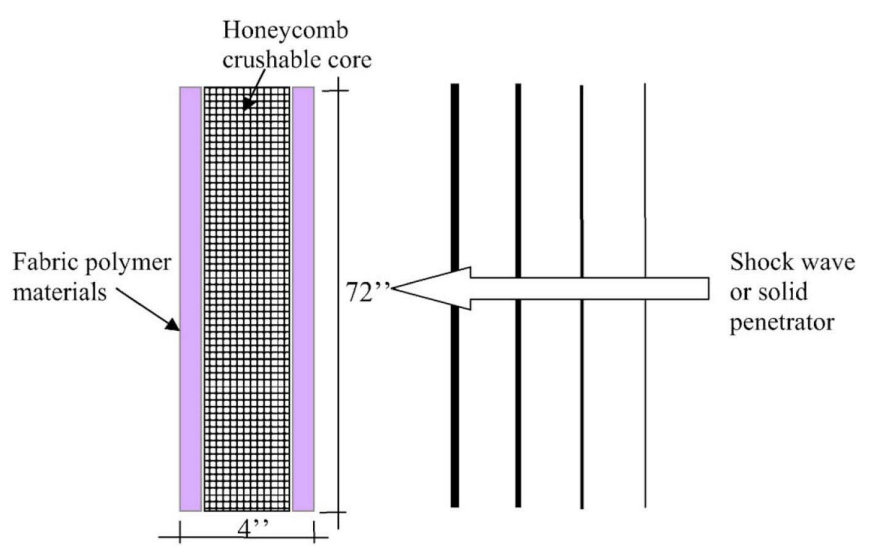

Figure 8. High energy absorbing sandwich structure.

\section{Example of a Hybrid Composite-Honeycomb Structure}

Classical structures use the multilayer materials to reduce the blast or impact effect over the protected structures. Many such configurations, such as armor, protective shelter, collision protective sandwich (Qiao et al., 2004), etc., are used in various civilian and defense applications. An innovative impact mitigation strategy involving the combined use of lowstrength porous honeycomb core material and fiber reinforced polymer composites has been explored in Yang and Qiao (2008a,b). Qiao and Yang (2007), for example (see Figure $8)$, study the impact response of honeycomb fiber-reinforced polymer composite sandwich beams with a unique sinusoidal core configuration (Davalos et al. 2001; Xu et al. 2001; Qiao and Wang 2005). The energy dissipation mechanisms consist of the plastic deformation, damping, and erosion of the target or projectile.

The design of protective sandwiches is realized through three different processes involved in the impact: elastic impact, elastic-plastic impact, and impact loading after densification. Using the crushing behavior of a honeycomb core (Yang and Qiao 2008a), a plate impact combined with core crushing behavior is proposed as (see Yang 2006)

$$
\begin{aligned}
& M \ddot{w}(t)=-P \text { with } \\
& P=\left\{\begin{array}{lll}
K_{h} \delta^{3 / 2} & \text { elastic loading, } & 0 \leqslant \delta \leqslant \delta_{\mathrm{y}} \\
P_{y} & \text { elastic plastic loading, } & \delta_{\mathrm{y}} \leqslant \delta \leqslant \delta_{\mathrm{d}} \\
K_{u}\left(\delta-\delta_{r}\right) & \text { unloading reloading, } & \delta_{\mathrm{r}} \leqslant \delta \leqslant \delta_{\mathrm{m}} \\
P_{y}+K_{D}\left(\delta-\delta_{r}\right) & \text { densification, } & \delta_{\mathrm{d}} \leqslant \delta \leqslant \delta_{\mathrm{m}}
\end{array}\right.
\end{aligned}
$$

where $M=$ mass of the projectile; $w=$ displacement of the project; $P_{y}=$ yielding (crushing) load; $K_{h}$ and $K_{u}=$ contact stiffness at loading and unloading stages, respectively; and $K_{D}=$ contact stiffness at densification.

The sandwich structure (parameters shown in Table 1) impacted by a passing object with a velocity of $10 \mathrm{~m} / \mathrm{s}(22.5 \mathrm{mi} / \mathrm{h})$ and a mass of $30 \mathrm{~kg}$ is simulated, and its deformation history is shown in Figure 9.

Table 1. Parameters of Sandwich Panels

\begin{tabular}{lllll}
\hline$K_{h}\left(\mathrm{~N} / \mathrm{m}^{3 / 2}\right)$ & $P_{y}(\mathrm{MPa})$ & $K_{u}(\mathrm{~N} / \mathrm{m})$ & $K_{D}(\mathrm{~N} / \mathrm{m})$ & $H(\mathrm{~mm})$ \\
\hline $6.02 \times 10^{7}$ & 0.72 & $3.04 \times 10^{6}$ & $9.35 \times 10^{6}$ & 100 \\
\hline
\end{tabular}

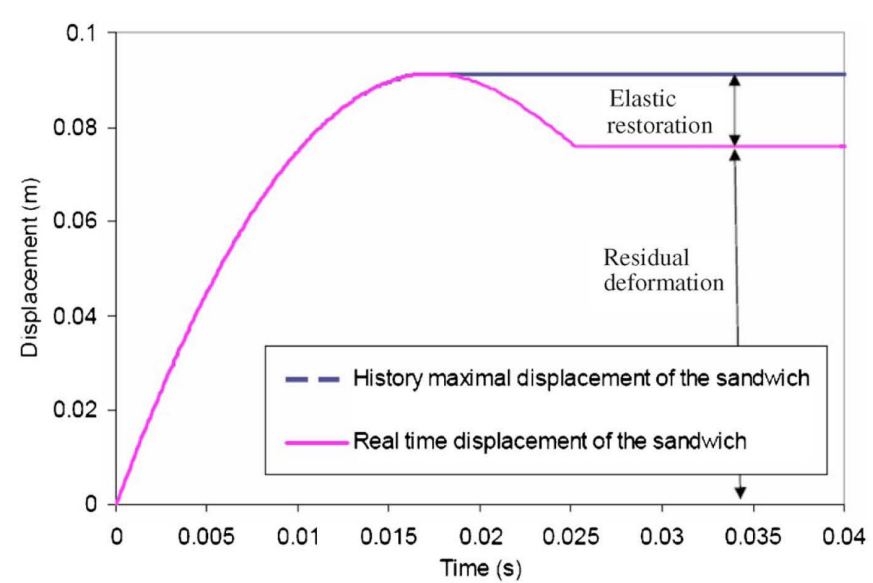

Figure 9. Deformation history of a sandwich panel impacted by a mass of $30 \mathrm{~kg}$ at a speed of $10 \mathrm{~m} / \mathrm{s}$.

From Figure 9, we observe that a permanent deformation of $75.80 \mathrm{~mm}$ is reached, corresponding to the case in which $76 \%$ of the core is crushed. The force time history is given in Figure 10. The peak contact force is $18.22 \mathrm{kN}$ over a contact area of 0.023 $\mathrm{m}^{2}$, which produces a compression stress of $0.792 \mathrm{MPa}(114.87$ psi); whereas the contact duration is $0.025 \mathrm{~s}$.

\section{Open Problems and Outlook}

Even though various designs have been proposed for different types of energy absorbing applications, specific designs for energy absorption must be conducted with great care as different phenomena happened at different time scales leading to interactions between incident pulses that may lead to a reversed effect on the target, as observed by Nesterenko (2001).

Significant efforts are currently directed toward designing and optimizing systems in which both the material and the structure provide energy dissipation mechanisms. For example, metal sandwich structures and multilayered metal-ceramic systems are areas of intense research at the moment. Heterogeneous materials appear to be a common theme for any successful energy absorbing system. A separate area of research, which we do not review here, is currently directed to designing or modifying the microstructure of polycrystalline ceramics to improve their impact performance.

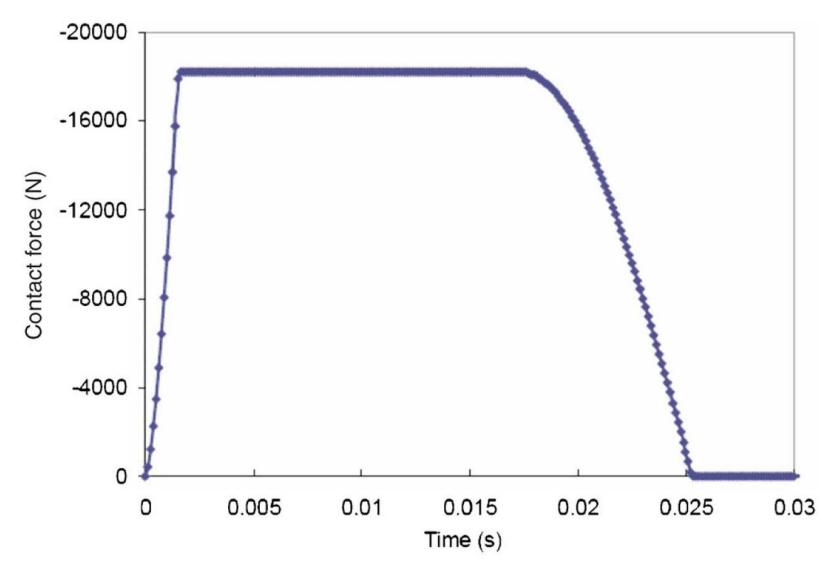

Figure 10. Contact force time history of the sandwich panel impacted by a mass of $30 \mathrm{~kg}$ at a speed of $10 \mathrm{~m} / \mathrm{s}$. 


\section{Concluding Remarks}

We review topics in impact mechanics and high energy absorbing structures and materials. A special attention is paid to several new concepts, both in terms of designs of new material systems and structures with energy absorbing properties (like lattice structures) and in terms of computational modeling of impact and fragmentation (such as mesh-free methods, and peridynamics). Experimental characterization and constitutive modeling of strain rate-dependent polymer matrix composites, and their implementation in micromechanics models and nonlinear finite-element code (e.g., LS-DYNA) for impact and failure analysis are briefly reviewed. Particular examples of high energy absorbing structures and materials are discussed, including multilayered materials (e.g., laminates and sandwich structures), lattice structures with waiting links and other unique materials (e.g., MR fluids and porous shape memory alloy). The potential application of sandwich structures in impact and blast mitigation is illustrated through a simple example.

Designing energy absorbing materials is challenging since various mechanisms - wave propagation, dynamic cracks, and delamination, thermal effects, dislocation generation, growth, and motion, etc. - are acting concurrently, at different material scales, and intertwined during impact. New research is needed especially in modeling and simulation of impact to be able to reach a point where models are predictive of the experimental results. Armed with such models, one can hope that optimal design of novel heterogeneous and anisotropic material systems with high energy absorption capabilities can become reality. Recent experiments on taped ceramic tiles show that ballistic performance can be improved significantly sometimes by only small increases in mass.

The design space, therefore, has solutions that are significantly better than the existing ones. Heterogeneous and anisotropic materials have useful features for mitigating damage when impacted because of many mechanisms of transforming the kinetic energy of the penetrator into: opening extensive crack surfaces and spreading (de-localizing) the damage zone; plastic deformation; buckling and other dynamic instabilities that change the material response. Judicious combination of research tools (theoretical, computational, and experimental) and multidisciplinary expertise (engineering, materials science, mechanics, physics, computations) will likely lead in the next decade to predictive models and optimization tools for novel material systems with significantly improved penetration resistance and energy absorbing capacity.

\section{References}

Ahmadian, M., Appleton, R., and Norris, J. (2002). “An analytical study of fire out of battery using magnetorheological dampers." Shock Vib., 9(3), 129-142.

Ahmadian, M., and Poynor, J. C. (2001). “An evaluation of magnetorheological dampers for controlling gun recoil dynamics." Shock Vib., 8(3-4), 141-146.

Ambur, D. R., Jaunky, N., Lawson, R. E., and Keight, N. F., Jr. (2001). "Numerical simulations for high-energy impact of thin plates." Int. J. Impact Eng., 25(7), 683-702.

Andrews, E. W., and Kim, K.-S. (1998). "Threshold conditions for dynamic fragmentation of ceramic particles." Mech. Mater., 29(3-4), 161-180.

Balk, A. M., Cherkaev, A. V., and Slepyan, L. I. (2001). “Dynamics of chains with non-monotone stress-strain relations. I. Model and numerical experiments." J. Mech. Phys. Solids, 49(1), 131-148.

Banerjee, B., Guilkey, J. E., Harman, T. B., Schmidt, J. A., and McMurty, P. A. (2005). "Simulation of impact and fragmentation with material point method." Proc., 11th Int. Conf. on Fracture, International Congress on Fracture (ICF), Turin, Italy.

Barenblatt, G. I. (1962). "The mathematical theory of equilibrium of cracks in brittle fracture." Adv. Appl. Mech., 7(1), 55-129.

Bazant, Z. P. (1991). “Why continuum damage is nonlocal: Micromechanics arguments." J. Eng. Mech., 117(5), 1070-1087.

Bazant, Z. P., and Jirasek, M. (2002). "Nonlocal integral formulations of plasticity and damage: Survey of progress." J. Eng. Mech., 128(11), 1119-1149.

Bazant, Z. P., and Lin, F.-B. (1988). “Nonlocal yield-limit degradation." Int. J. Numer. Methods Eng., 26(8), 1805-1823.

Belytschko, T., Liu, W. K., and Moran, B. (2000). Nonlinear finiteelements for continua and structures, Wiley, New York.

Belytschko, T., Lu, Y. Y., and Gu, L. (1994). “Element-free Galerkin methods." Int. J. Numer. Methods Eng., 37(2), 229-256.

Belytschko, T., Lu, Y. Y., Gu, L., and Tabbara, M. (1995). “Elementfree Galerkin methods for static and dynamic fracture." Int. J. Solids Struct., 32(17-18), 2547-2570.

Belytschko, T., and Tabbara, M. (1996). "Dynamic fracture using element-free Galerkin methods." Int. J. Numer. Methods Eng., 39(6), 923-938.

Binienda, W. K. (2004). "High energy impact of composite structures - Ballistic experiments and explicit finite-element analysis." Rep., submitted to NASA Glenn Research Center, The Univ. of Akron, Akron, Ohio.

Bobaru, F. (2007). "Influence of van der Waals forces on increasing the strength and toughness in dynamic fracture of nanofiber networks: A peridynamic approach." Modell. Simul. Mater. Sci. Eng., 15(5), 397- 417.

Bobaru, F., Yang, M., Alves, L. F., Silling, S. A., Askari, E., and Xu, J. (2008). "Convergence, adaptive refinement, and scaling in 1D peridynamics." Int. J. Numer. Methods Eng., in press.

Bordonaro, C. M. (1995). "Rate dependent mechanical behavior of high strength plastics: Experiment and modeling." Ph.D. thesis, Rensselaer Polytechnic Institute, Troy, NY.

Brach, R. M. (1991). Mechanical impact dynamics: Rigid body collisions, Wiley, New York.

Camacho, G. T., and Ortiz, M. (1997). “Adaptive Lagrangian modelling of ballistic penetration of metallic targets." Comput. Meth. Appl. Math., 142(3-4), 269-301.

Caprino, G., and Teti, R. (1994). "Impact and post impact behavior of foam core sandwich structures." Compos. Struct., 29(1), 47-55.

Chang, W. J., and Pan, J. (1997). “Effects of yield surface shape and round-off vertex on crack-tip fields for pressure-sensitive materials." Int. J. Solids Struct., 34(25), 3291-3320.

Chen, Y., Lee, J., and Eskandarian, A. (2004). “Atomistic viewpoint of the applicability of micro-continuum theories." Int. J. Solids Struct., 41(8), 2085-2097.

Cheng, J., and Binienda, W. K. (2006). "Simulation of soft projectiles impacting composite targets using an arbitrary Lagrangian-Eulerian Formulation." J. Aircr., 43(6), 1726-1731.

Cheng, J., and Binienda, W. K. (2008). "Simplified braiding through integration points model for triaxially braided composites." J. Aerosp. Eng., 21(3), 119-131.

Cheng, M., McCauley, J., and Hemker, K. (2003). "Shock-induced localized amorphization in Boron Carbide." Science, 299(7), 1563-1566. 
Cherkaev, A., and Slepyan, L. (1995). “Waiting element structures and stability under extension." Int. J. Damage Mech., 4(1), 58-82.

Conrad, M. M., and Sayir, M. B. (1998). “Optical methods in impact and vibrations." http://www.ifm.mavt.ethz.ch/research/ contents.html or http://www.zfm.ethz.ch/e/abo/adr/index. $\underline{\mathrm{htm}}$

Cox, B., and Yang, Q. D. (2006). "In quest of virtual test for structural composites." Science, 314(5802), 1102-1107.

Dancila, D. S., and Armanios, E. A. (2002). "Energy-dissipating composite members with progressive failure: Concept development and analytical modeling." AIAA J.,40(10), 2096-2104.

Daniel, I. M., Hsiao, H. M., and Cordes, R. D. (1995). “Dynamic response of carbon/epoxy composites." High strain rate effects on polymer, metal and ceramic matrix composites and other advanced materials, AD-Vol. 48, Y. D. S. Rajapakse and J. R. Vinson, eds., American Society of Mechanical Engineers (ASME), Washington, D.C., 167-177.

Davalos, J. F., Qiao, P., Xu, X. F., Robinson, J., and Barth, K. E. (2001). "Modeling and characterization of fiber-reinforced plastic honeycomb sandwich panels for highway bridge applications." Compos. Struct., 52(3-4), 441-452.

Davies, G. A. O., Hitchings, D., and Wang, J. (1995). "Prediction of thresholds of glass fiber reinforced laminates." Compos. Struct., 31(1), 185-193.

Dobyns, A. L., and Porter, T. R. (1981). “A study of the structural integrity of graphite composite structure subjected to a low velocity impact." Polym. Eng. Sci., 21(8), 493-498.

Dugdale, D. S. (1960). "Yielding of steel sheets containing slits." J. Mech. Phys. Solids, 8(1), 100-108.

El Wahed, A. K., Sproston, J. L., and Schleyer, G. K. (2002). “Electrorheological and magnetorheological fluids in blast resistant design applications." Mater. Des., 23(4), 391-404.

Eringen, A. C. (1981). “On nonlocal plasticity.” Int. J. Eng. Sci., 19(12), 1461-1474.

Erofeyev, V. I. (2003). Wave processes in solids with microstructure, World Scientific, Singapore.

Evans, A. G., Hutchinson, J. W., Fleck, N. A., Ashby, M. F., and Wadley, H. N. G. (2001). "The topological design of multifunctional cellular metals." Prog. Mater. Sci., 46(3-4), 309-327.

Fahrenthold, E. P., and Horban, B. A. (2001). "An improved hybrid particle-element method for hypervelocity impact simulation." Int. J. Impact Eng., 26(1-10), 169-178.

Fleck, N. A., and Deshpande, V. S. (2004). "The resistance of clamped sandwich beams to shock loading." J. Appl. Mech., 71(3), 386-401.

Gao, H., and Huang, Y. (2001). "Taylor-based nonlocal theory of plasticity." Int. J. Solids Struct., 38(42-43), 2615-2637.

Gilat, A., Goldberg, R. K., Roberts, and G. (2005). “Strain rate sensitivity of epoxy resin in tensile and shear loading." NASA Tech. Memo., 2005-213595, NASA Glenn, Cleveland, Ohio.

Gingold, R. A., and Monaghan, J. J. (1977). "Smoothed particle hydrodynamics - Theory and application to non-spherical stars." Mon. Not. R. Astron. Soc., 181(2), 375-389.

Goldberg, R. K., Roberts, G. D., and Gilat, A. (2005). “Implementation of an associative flow rule including hydrostatic stress effects into the high strain rate deformation analysis of polymer matrix composites." J. Aerosp. Eng., 18(1), 18-27.

Goldberg, R. K., Roberts, G. D., Littell, J. D., and Binienda, W. K. (2008). "Approximation of nonlinear unloading effects in the strain rate dependent deformation analysis of polymer matrix materials utilizing a state variable approach." J. Aerosp. Eng., 21(3), 119-131.
Goldsmith, W. (1960). Impact, Arnold, London.

Goldsmith, W., and Sackman, J. L. (1992). “An experimental study of energy absorption in impact on sandwich plates." Int. J. Impact Eng., 12(2), 241-262.

Guruprasad, S., and Mukherjee, A. (2000). "Layered sacrificial claddings under blast loading, I: Analytical studies." Int. J. Impact Eng., 24, 957-973.

Ha, K., and Dancila, D. S. (2003). "Energy-dissipating snap-resistant tether." AIAA 41st Aerospace Sciences Meeting and Exhibit.

Hallquist, J. O. (1993). LS-DYNA3D theoretical manual, Livermore Software Technology Corporation, Livermore, Calif., 135-180.

Hallquist, J. O., Goudreau, G. L., and Bension, D. J. (1985). “Sliding interfaces with contact-impact in large-scale Lagrangian computations." Comput. Methods Appl. Mech. Eng., 51(1-3), 107-137.

Hamza, K., and Saitou, K. (2005). “Design optimization of vehicle structures for crashworthiness using equivalent mechanism approximations." J. Mech. Des., 127(3), 485-492.

Hexcel Corporation. (1964). "Design data for the preliminary selection of honeycomb energy absorption systems." Rep. No. TSB 122, Stamford, Conn.

Hexcel Corporation. (1968). "Mechanical properties of hexcel honeycomb materials." Rep. No. TSB 120, Stamford, Conn.

Hogg, P. J. (2006). “Composites in armor.” Science, 314(5802), 1100- 1101.

Jamjian, M., Sackman, J. L., and Goldsmith, W. (1994). “Responses of an infinite plate on a honeycomb foundation to a rigid cylindrical impactor." Int. J. Impact Eng., 15(3), 183-200.

Johnson, G. R., and Stryk, R. A. (2003). "Conversion of 3D distorted elements into meshless particles during dynamic deformation." Int. J. Impact Eng., 28(9), 947-966.

Johnson, G. R., Stryk, R. A., Beissel, S. R., and Holmquist, T. J. (2001). "Conversion of finite-elements into meshless particles for penetration computations involving ceramic targets." Proc., 12th APS Topical Conf. on Shock Compression of Condensed Matter, American Physical Society, College Park, Md., 1287-1290.

Johnson, K. L. (1985). Contact mechanics, Cambridge University Press, Cambridge, UK.

Jolly, M. R. (2000). “Properties and applications of magnetorheological fluids." Mater. Res. Soc. Symp. Proc., MRS, Warrendale, Pa., 604, 167-176.

Jones, S. E., Maudlin, A. E., and Foster, J. C. (1997). “An engineering analysis of plastic wave propagation in the Taylor test." Int. J. Impact Eng., 19(2), 95-106.

Kang, Y. S., Kikuchi, K., and Kawasaki, A. (2001). "Fabrication and characterization of functionally graded $\mathrm{Ni} / \mathrm{Al}_{2} \mathrm{O}_{3} / \mathrm{Ni}$ compliant pad." Proc. ISSPS, Singapore.

Kolsky, H. (1963). Stresses waves in solids, Dover, New York.

Kunin, I. A. (1982). Elastic media with microstructure, Vols. I and II, Springer, Berlin.

Lee, D. Y., Choi, Y. T., and Wereley, M. N. (2002). "Performance analysis of ER/MR impact damper systems using HerschelBulkley model." J. Intell. Mater. Syst. Struct., 13(7-8), 525-531.

Lee, M., and Yoo, Y. H. (2001). “Analysis of ceramic/metal armour system." Int. J. Impact Eng., 25(9), 819-829.

Lee, Y. S., Wetzel, E. D., and Wagner, N. J. (2003). “The ballistic impact characteristics of Kevlar woven fabrics impregnated with a colloidal shear thickening fluid." J. Mater. Sci., 38(13), 2825-2833.

Li, F. Z., and Pan, J. (1990). “Plane-stress crack-tip fields for pressure-sensitive dilatant materials." J. Appl. Mech., 57(1), 40-49. 
Libersky, L. D., and Petschek, A. G. (1991). “Smoothed particle hydrodynamics with strength of materials." Proc., Next FreeLagrange Conf., W. P. Crowley, M. J. Fritts, H. E. Trease eds., Springer, Berlin, 248-257.

Lim, T. S., Lee, C. S., and Lee, D. G. (2004). "Failure modes of foam core sandwich beams under static and impact loads." J. Compos. Mater., 38(18), 1639-1662.

Littell, J. D., Ruggeri, C. R., Goldberg, R. K., Roberts, G. D., Arnold, W. A., and Binienda, W. K. (2008). "Measurement of epoxy resin tension, compression, shear stress-strain curves over a wide range of strain rates and temperatures." J. Aerosp. Eng., 21(3), 162-173.

Liu, W. K., Li, S. F., and Belytschko, T. (1997). "Moving least square reproducing kernel method. 1: Methodology and convergence." Comput. Methods Appl. Mech. Eng., 143(1-2), 113-154.

Lopez-Puente, J., Arias, A., Zaera, R., and Navarro, C. (2005). “The effect of the thickness of the adhesive layer on the ballistic limit of ceramic/metal armours. An experimental and numerical study." Int. J. Impact Eng., 32, 321-336.

Lucy, L. B. (1977). "Numerical approach to testing of fission hypothesis." Astron. J.,82(12), 1013-1024.

Magee, C. L., and Thornton, P. H. (1978). “Design consideration in energy absorption by structural collapse." SAE Rep. No. 78434, Society of Automotive Engineers, Warrendale, Pa.

Matemilola, S. A., and Strong, W. J. (1995). "Impact induced dynamic deformation and stresses in CFRP composite laminates." Composites Eng., 5(2), 211-222.

McFarland, R. K. (1963). "Hexagonal cell structures under postbuckling axial load." AIAA J.,1(6), 1380-1385.

Meyers, M. A. (1994). Dynamic behavior of materials, Wiley, New York.

Miyoshi, T., et al. (1999). "Enhancement of energy absorption in closed-cell aluminum by the modification of cellular structures." J. Phys.: Condens. Matter, 41(10), 1055-1060.

Molinari, A., and Ravichandran, G. (2004). "Fundamental structure of steady plastic shock waves in metals." J. Appl. Phys., 95(4), 1718- 1732.

Mota, A., Klug, W. S., Ortiz, M., and Pandolfi, A. (2003). “Finiteelement simulation of firearm injury to the human cranium." Comput. Mech., 31(1-2), 115-121.

Needleman, A. (1987). “A continuum model for void nucleation by inclusion debonding." J. Appl. Mech., 54(3), 525-531.

Nemat-Nasser, S., Kang, W. J., McGee, J. D., Guo, W.-G., and Isaacs, J. B. (2007). “Experimental investigation of energy-absorption characteristics of components of sandwich structures." Int. J. Impact Eng., 34(6), 1119-1146.

Nesterenko, V. F. (2001). Dynamics of heterogeneous materials, Springer, New York.

Ortiz, M., and Pandolfi, A. (1999). "Finite-deformation irreversible cohesive elements for three-dimensional crack-propagation analysis." Int. J. Numer. Methods Eng., 44(9), 1267-1282.

Pandolfi, A., Krysl, P., and Ortiz, M. (1999). “Finite-element simulation of ring expansion and fragmentation, The capturing of length and time scales through cohesive models of fracture." Int. J. Fract., 95(1-4), 279-297.

Park, Y. K., and Fahrenthold, E. P. (2005). "A kernel free particlefinite-element method for hypervelocity impact simulation." Int. J. Numer. Methods Eng., 63(5), 737-759.

Parks, M. L., Lehoucq, R. B., Plimpton, S. J., and Silling, S. A. (2008). "Implementing peridynamics within a molecular dynamics code." Comput. Phys. Commun., in press (available online June 26, 2008).
Pedersen, C. B. W. (2002). “Topology optimization of energy absorbing frames." WCCM V, 5th World Congress on Computational Mechanics, H. A. Mang, F. G. Rammerstorfer, and J. Eberhardsteiner, eds., Vienna, Austria.

Pedersen, C. B. W. (2003). "Topology optimization of 2D-frame structures with path-dependent response." Int. J. Numer. Methods Eng., 57(10), 1471-1501.

Polizzotto, C., Borino, G., and Fuschi, P. (1998). "A thermodynamic consistent formulation of nonlocal and gradient plasticity." Mech. Res. Commun., 25(1), 75-82.

Pouget, J. (1992). "Stability of nonlinear structures in a lattice model for phase transformations in alloys." Phys. Rev. B,46(17), 10554-10562.

Pouget, J. (1993). "Lattice dynamics and stability of modulatedstrain structures for elastic phase transitions in alloys." Phys. Rev. B,48(2), 864-875.

Qiao, P., and Bibienda, W. K. (2008). "Impact mechanics of composite materials for aerospace application." J. Aerosp. Eng., 21(3), 117-118.

Qiao, P., and Wang, J. L. (2005). “Mechanics of composite sinusoidal honeycomb cores." J. Aerosp. Eng., 18(1), 42-50.

Qiao, P., and Yang, M. J. (2007). "Impact analysis of fiber reinforced polymer honeycomb composite sandwich beams." Composites, Part B,38(5-6), 739-750.

Qiao, P., Yang, M. J., and Mosallam, A. S. (2004). “Impact analysis of I-Lam sandwich system for over-height collision protection of highway bridges." Eng. Struct., 26(7), 1003-1012.

Rathbun, H. J., et al. (2006). "Performance of metallic honeycomb-core sandwich beams under shock loading." Int. J. Solids Struct., 43(6), 1746-1763.

Reid, S. R., and Zhou, G. (2000). Impact behavior of fiber reinforced composite materials and structures, CRC Press, Boca Raton, Fla.

Repetto, E. A., Radovitzky, R., and Ortiz, M. (2000). “Finite-element simulation of dynamic fracture and fragmentation of glass rods." Comput. Methods Appl. Mech. Eng., 183(1-2), 3-14.

Rogula, D. (1982). Nonlocal theory of material media, Springer, Berlin.

Sarva, S., Nemat-Nasser, S., McGee, J., and Isaacs, J. (2007). “The effect of thin membrane restraint on the ballistic performance of armor grade ceramic tiles." Int. J. Impact Eng., 34(2), 277-302.

Shim, V. W., Tan, V. B. C., and Tay, T. E. (1995). "Modeling deformation and damage characteristics of woven fabric under small projectile impact." Int. J. Impact Eng., 16(14), 585-605.

Shipsha, A. Hallstrom, S., and Zenkert, D. (2003). "Failure mechanisms and modeling of impact damage in sandwich beamsA 2D approach. I: Experimental investigation." J. Sandwich Struct. Mater., 5(1), 7-32.

Shivarama, R., and Fahrenthold, E. P. (2004). "An ellipsoidal particle-finite-element method for hypervelocity impact simulation." Int. J. Numer. Methods Eng., 59(5), 737-753.

Silling, S. A. (2000). "Reformulation of elasticity theory for discontinuities and long-range forces." J. Mech. Phys. Solids, 48(1), 175-209.

Silling, S. A., and Askari, E. (2005). "A meshfree method based on the peridynamic model of solid mechanics." Comput. Struct., 83(17-18), 1526-1535.

Silling, S. A., and Bobaru, F. (2005). "Peridynamic modeling of membranes and fibers." Int. J. Non-Lin. Mech., 40(2-3), 395-409.

Silling, S. A., Epton, M., Weckner, O., Xu, J., and Askai, E. (2007). "Peridynamic states and constitutive modeling." J. Elast., 88(2), 151- 184. 
Silling, S. A., Zimmermann, M., and Abeyaratne, R. (2003). “Deformation of a peridynamic Bar." J. Elast., 73(1-3), 173-190.

Slepyan, L. I., and Ayzenberg-Stepanenko, M. V. (2004). "Localized transition waves in bistable-bond lattices." J. Mech. Phys. Solids, 52(7), 1447-1479.

Soto, C. A. (2004). "Structural topology optimization for crashworthiness." Int. J. Crashworthiness, 9(3), 277-283.

Sulsky, D., Chen, Z., and Schreyer, H. L. (1994). “A particle method for history dependent materials." Comput. Methods Appl. Mech. Eng., 118(1-2), 179-196.

Sulsky, D., Zhou, S., and Schreyer, H. L. (1995). "Application of a particle-in-cell method to solid mechanics." Comput. Phys. Commun., 87(1-2), 236-252.

Svedberg, T. (1996). "A thermodynamically consistent theory of gradient-regularized plasticity coupled to damage." Licentiate thesis, Chalmers Univ. of Technology, Chalmers, Sweden.

Swegle, J. W., Hicks, D. L., and Attaway, S. W. (1995). “Smoothed particle hydrodynamics stability analysis." J. Comput. Phys., 116(1), 123-134.

Taylor, W. J., and Vinson, J. R. (1990). “Modeling ballistic impact into flexible materials." AIAA J.,28(12), 2098-2103.

Thomsen, O. T. (1995). "Theoretical and experimental investigation of local bending effects in sandwich plates." Compos. Struct., 30(1), 85-101.

Tsai, C. Z., Wu, E., and Luo, B. H. (1998). “Forward and inverse analysis for impact on sandwich panels." AIAA J.,36(11), 2130-2136.

Turk, M. H., and Hoo-Fatt, M. S. (1999). "Localized damage response of composite sandwich plates." Composites, Part B,30(2), 157-165.

Vaziri, A., and Hutchinson, J. W. (2007). "Metal sandwich plates subject to intense air shocks." Int. J. Solids Struct., 44(6), 2021-2035.

Vaziri, A., Xue, Z., and Hutchinson, J. W. (2006). "Metal sandwich plates with polymeric foam-filled cores." J. Mech. Mater. Struct., 1(1), 95- 128.

Wang, F. J., Wang, L. P., Cheng, J. G., and Yao, Z. H. (2007). “Contact algorithm in explicit transient analysis using finite-element method." Finite Elem. Anal. Design, 43(6-7), 580-587.

Weckner, O., and Abeyaratne, R. (2005). "The effect of long range forces on the dynamics of a bar." J. Mech. Phys. Solids, 53(3), 705-728.

Weckner, O., and Emmrich, E. (2005). “Numerical simulation of the dynamics of a nonlocal inhomogeneous, infinite bar." J. Comput. Appl. Mech., 6(2), 311-319.

Wierzbicki, T. (1983). "Crushing analysis of metal honeycombs." Int. J. Impact Eng., 1(1), 157-174.

Wierzbicki, T., Alvarez, A., and Hoo Fatt, M. S. (1995). “Impact energy absorption of sandwich plates with crushable core." AMD-205, Proc., 1995 Joint ASME Applied Mechanics \& Materials Summer Meeting, American Society of Mechanical Engineers (ASME), Washington, D.C.

Wriggers, P., Vu Van, T., and Stein, E. (1990). “Finite-element formulation of large deformation impact-contact problems with friction." Comput. Struct., 37(3), 319-331.

Xie, W. (2005). "Peridynamic flux-corrected transport algorithm for shock wave studies." Master thesis, The Univ. of NebraskaLincoln, Lincoln, Neb.

Xu, J., Askari, A., Weckner, O., and Silling, S. A. (2008. "Peridynamic analysis of impact damage in composite laminates." J. Aerosp. Eng., 21(3), 174-186.
Xu, X. F., Qaio, P., and Davalos, J. F. (2001). “Transverse shear stiffness of composite honeycomb core with general configuration." J. Eng. Mech., 127(11), 1144-1151.

Xue, Z., and Hutchinson, J. W. (2004). “A comparative study of impulse-resistant metal sandwich plates." Int. J. Impact Eng., 30, 1283-1305.

Yang, G. Q., Spencer, B. F. Jr., Jung, H.-J., and Carlson, J. D. (2004). "Dynamic modeling of large-scale magnetorheological damper systems for civil engineering applications." J. Eng. Mech., 130(9), 1107- 1114.

Yang, M. J. (2006). "Impact mechanics of elastic and elastic-plastic sandwich structures." Ph.D. dissertation, The Univ. of Akron, Akron, Ohio.

Yang, M. J., and Qiao, P. (2005a). "Higher-order impact modeling of sandwich beams with flexible core." Int. J. Solids Struct., 42(20), 5460-5490.

Yang, M. J., and Qiao, P. (2005b). “Nonlinear impact analysis of fully-backed composite sandwich structures." Compos. Sci. Technol., 65(3- 4), 551-562.

Yang, M. J., and Qiao, P. (2007). “Impact and damage prediction of sandwich beams with flexible core considering arbitrary boundary effects." J. Sand. Struct. Mater., 9(5), 411-444.

Yang, M. J., and Qiao, P. (2008a). "Quasistatic crushing behavior of aluminum honeycomb materials." J. Sandwich Struc. Mater., 10(2), 133-160.

Yang, M. J., and Qiao, P. (2008b). "Quasistatic indentation behavior of honeycomb sandwich materials and its application in impact simulations." J. Aerosp. Eng., 21(4), 266-234.

Zhang, Y. G., and Ballmann, J. (1996). "An explicit finite-difference procedure for contact-impact analysis of crack edges." Arch. Appl. Mech., 66(7), 493-502.

Zhao, Y., Taya, M., and Izui, H. (2006). “Study on energy absorbing composite structure made of concentric NiTi spring and porous NiTi." Int. J. Solids Struct., 43(9), 2497-2512.

Zhao, Y., Taya, M., Kang, Y. S., and Kawasaki, A. (2005). “Compression behavior of porous NiTi shape memory alloy." Acta Mater., 53(2), 337-343.

Zheng, X., and Binienda, W. K. (2008). "Rate dependent shell element composite material model implementation in LS-DYNA." J. Aerosp. Eng., 21(3), 140-151.

Zhong, Z. H. (1993). Finite-element procedures for contact-impact problems, Oxford University Press, Oxford, U.K..

Zhou, F. H., Molinari, J.-F., and Armes, K. T. (2005). "A cohesive model based fragmentation analysis: Effects of strain rate and initial defects distribution." Int. J. Solids Struct., 42(18-19), 5181-5207.

Zhu, L. F., Chattopadhyay, A., and Goldberg, R. K. (2006).“A 3Dmicromechanics model for strain rate dependent inelastic polymer matrix composites." 47th AIAA/ASME/ASCE/AHS/ ASC Structures, Structural Dynamics \& Materials Conf., Newport, R.I.

Zhu, L. F., Chattopadhyay, A., and Goldberg, R. K. (2008). “Failure model for rate dependent polymer matrix composite laminates under high velocity impact." J. Aerosp. Eng., 21(3), 132-139.

Zukas, J. A. (2004). Introduction to hydrocodes, Elsevier, New York.

Zukas, J. A., Nicholas, T., Swift, H. F., Greszczuk, L. B., and Curran, D. R. (1992). Impact dynamics, Krieger, Malabar, Fla.

Zukas, J. A., and Scheffler, D. R. (2001). "Impact effects in multilayered plates." Int. J. Solids Struct., 38, 3321-3328. 